doi: ISSN 0103-5150

Fisioter. Mov., Curitiba, v. 26, n. 4, p. página 763-775, set./dez. 2013

Licenciado sob uma Licença Creative Commons

\title{
A interface entre bioética e fisioterapia nos artigos brasileiros indexados
}

\section{The interface between bioethics and physiotherapy in Brazilian indexed papers}

\section{Cláudio Fortes Garcia Lorenzo ${ }^{[a]}$, Gláucia Teles Araújo Bueno ${ }^{[b]}$}

[a] Doutor em Ética Aplicada à Pesquisa pela Université de Sherbrooke, professor adjunto do Departamento de Saúde Coletiva da Universidade de Brasília (UnB), professor do Programa de Pós-Graduação em Bioética da mesma instituição, presidente da Sociedade Brasileira de Bioética, Brasília, DF - Brasil, e-mail: claudiolorenzo.unb@gmail.com.

[b] Fisioterapeuta, mestranda no Programa de Pós-Graduação em Bioética da Universidade de Brasília (UnB), Brasília, DF - Brasil, e-mail: glaucia_teles@yahoo.com.br

\section{Resumo}

Introdução: Apesar de ainda muito incipiente a aproximação entre fisioterapia e bioética no Brasil, tem sido crescente a preocupação com o seu desenvolvimento devido à variedade de conflitos éticos que podem envolver os fisioterapeutas. $\mathrm{O}$ objetivo deste artigo foi fazer um estudo sobre as temáticas e a fundamentação teórica dos artigos indexados que pretendiam discutir a interface entre fisioterapia e bioética. Materiais e métodos: Trata-se de estudo de análise de conteúdo pelo método de Bardin em todos os artigos publicados em revistas indexadas, encontrados nas fontes BIREME e SciELO entre 2000 e 2011, utilizando os descritores: fisioterapia e bioética e seus derivados. Resultados: Confirmou-se o nível primário do desenvolvimento da reflexão bioética em fisioterapia, mostrando deficiências conceituais, distanciamento das teorias mais modernas e dos modelos desenvolvidos no Brasil e falta de consideração dos contextos socioculturais e econômicos como elementos que influenciam a geração de conflitos. Considerações finais: Apontou-se a necessidade de desenvolver projetos de capacitação em bioética para professores e pesquisadores da área de fisioterapia, com vistas ao desenvolvimento de conteúdos nos programas de graduação e pós-graduação.

Palavras-chave: Bioética. Ética baseada em princípios. Fisioterapia. Teoria ética. Educação. 


\section{Abstract}

Introduction: Although still incipient rapprochement between Physical Therapy and Bioethics in Brazil has been growing concern about its development due to the variety of ethical conflicts that may involve physiotherapists. This paper was a study on the themes and the theoretical foundation of the articles indexed wishing to discuss the interface between Physical Therapy and Bioethics. Materials and methods: This study was conducted by content analysis method Bardin in all papers published in refereed journals, found in the sources BIREME and SciELO between 2000 and 2011 using the keywords: physiotherapy and bioethics and its derivatives. Results: We confirmed the primary level of development of bioethical reflection in physical therapy, showing conceptual deficiencies, distance of more modern theories and models developed in Brazil and lack of consideration of sociocultural and economic factors as influencing the generation of conflict. Final thoughts: It was pointed out the need to develop training projects in bioethics for teachers and researchers in the field of physical therapy in order to develop content in undergraduate programs and graduate.

Keywords: Bioethics. Principle-based ethics. Physical therapy. Ethics theory. Education.

\section{Introdução}

A bioética pode ser conceituada como um estudo interdisciplinar no âmbito das ciências da vida e da atenção à saúde, orientado para a análise de tomada de decisões, formulação de juízos práticos e políticos sobre escolhas, decisões e atos voltados à luz de valores e princípios morais $(1,2)$. Ela envolve, portanto, diferentes domínios acadêmicos, científicos, técnicos e profissionais, projetando-se para um campo de atividades que se encontra além das perspectivas particulares das disciplinas que a constituem (3).

Surgida nos Estados Unidos, a bioética expandiu-se pelo mundo, sobretudo por meio do modelo principialista de Beuchamp e Childress (4), formulado no fim dos anos 70 do século passado e baseado em quatro princípios que se pretendiam universais: autonomia, beneficência, não maleficência e justiça. Já em torno de 1990, a comunidade acadêmica começou a reconhecer que, apesar deste ter sido um referencial útil para orientar as tomadas de decisões, ele mostrava-se insuficiente para resolver conflitos éticos em situações clínicas mais complexas (5). Data desse período também o início do desenvolvimento de um pensamento bioético brasileiro voltado e contextualizado para as necessidades dos países latino-americanos (6), com mais preocupações sanitárias e atenção aos conflitos provocados pelas situações de exclusão à saúde historicamente determinadas.

0 exercício da fisioterapia, como de qualquer outra profissão de saúde, é permeado por diversos conflitos éticos. Entre os que têm sido mais discutidos cotidianamente encontram-se, além dos clássicos envolvendo terminalidade da vida ou prematuridade extrema, aqueles em torno da autonomia dos pacientes, como a recusa de tratamentos cientificamente comprovados ou tomadas de decisão quando essa autonomia está limitada por situações como senilidade, infância e distúrbios mentais ou neurológicos. Outros estão diretamente ligados ao sigilo e à confidencialidade de informações obtidas no exercício de práticas domiciliares de assistência, e outros são provocados pelas relações interprofissionais em torno das decisões de tratamento ou quanto à legitimidade no domínio de práticas e atos que pertencem a mais de uma categoria profissional.

Todos esses conflitos interpessoais aqui descritos sofrem influência direta dos contextos socioculturais que os envolvem, mas alguns surgem mais especificamente desses próprios contextos e da organização sociopolítica de atenção à saúde, com vistas a garantir a sujeitos e comunidades o respeito ao direito a um tratamento fisioterapêutico eficaz. Entre eles poderíamos citar: a deficiência de políticas públicas para essa assistência; a permissão às seguradoras privadas de oferta de um número de sessões de tratamento sabidamente insuficientes; ou ainda as condições de trabalho adversas e a escassez de recursos em muitas instituições. Uma abordagem dessas questões teria elos ainda mais fortes com a bioética propriamente brasileira e latino-americana.

Nos últimos anos houve um significativo aumento do reconhecimento da bioética como conteúdo fundamental para uma formação profissional no Brasil. Surgiram muitos programas de educação continuada, cursos de especialização e programas de pós-graduação em bioética, além do surgimento de núcleos nacionais de pesquisas em bioética que proporcionaram 
um aumento significativo da produção científica brasileira na área $(7,8)$, a qual vem sendo internacionalmente reconhecida por sua identidade e temáticas próprias. Entretanto, essa tendência não parece ter alcançado ainda o campo da fisioterapia.

As temáticas que envolvem a bioética e a fisioterapia no Brasil estiveram ao longo da história da profissão fundamentadas em conceitos deontológicos, limitadas ao código de ética profissional e aos aspectos legais. Badaró e Guilhem (9) demonstraram que no cenário nacional a pesquisa envolvendo bioética e fisioterapia só emergiu a partir de 2002, enquanto a produção estadunidense, mesmo escassa, é apontada desde 1970 e ressaltou a escassez de discussões a partir de conceitos bioéticos modernos e da aplicabilidade destes na prática clínica.

Ainda não existem, entretanto, estudos sistematizados sobre as publicações nacionais indexadas que envolvem a bioética no âmbito da prática fisioterápica, procurando identificar o conceito de bioética utilizado pelos autores, a escolha dos temas e correntes teóricas e o grau de aprofundamento das discussões. 0 objetivo deste trabalho foi exatamente produzir uma busca sistematizada sobre todos os artigos publicados em revistas nacionais indexadas, entre 2000 e 2011, nas quais, entre os objetivos principais, estivessem as relações teóricas ou práticas entre fisioterapia e bioética, e realizar uma análise de conteúdo nos artigos encontrados, com vistas a identificar seus temas e suas fundamentações teóricas em bioética.

\section{Pensando uma bioética para a fisioterapia}

De acordo com Garrafa (5), a história da bioética pode ser brevemente descrita em quatro fases. As duas primeiras fases, entre as décadas de 1970 e 1980, foram notadamente marcadas pela sua fundação, consolidação e expansão da nova disciplina. A segunda fase da expansão foi caracterizada pela afirmação do principialismo como principal corrente da bioética em praticamente todos os continentes. Mesmo considerada tardia, a bioética no Brasil sofreu significativa influência do modelo principialista (10). A terceira fase dá-se na década de 1990 e foi marcada pelo surgimento de críticas ao principialismo, permitindo a ampliação dos campos teórico e prático da bioética. Nessa fase, a comunidade acadêmica passa a reconhecer que esse modelo mostrava-se insuficiente para dirimir as dúvidas em situações clínicas mais complexas, sobretudo quando influenciadas por contextos de injustiças sociais e diversidades culturais (5). Proliferam-se aqui diversas propostas de modelos teóricos alternativos para tomadas de decisão na prática clínica e para ampliação dos campos de atuação da bioética. Finalmente, a última fase, que se inicia na virada do século XXI e se mantém até o presente momento, vem ressaltando a necessidade de enfrentar de um modo mais ético e concreto as questões sociais e sanitárias, e de garantir a universalidade do acesso de indivíduos e comunidades aos benefícios do desenvolvimento científico e tecnológico. É a partir desse momento que os modelos teóricos brasileiro e latino-americano, voltados para as necessidades sociais e características culturais de suas regiões, ganham maior relevância e reconhecimento (6). Entre esses modelos destacam-se a bioética de intervenção de Garrafa e Porto (11) e a bioética de proteção de Schramm e Kottow (12).

É possível afirmar que a Declaração Universal de Bioética e Direitos Humanos da Unesco (13), publicada em 2005, vem reafirmar a pertinência dessas novas formas de conceber a bioética na medida em que reconhece os conflitos bioéticos provocados por razões socioeconômicas e culturais e toma as questões de saúde pública como questões próprias da bioética.

Ao longo das duas últimas décadas, disciplinas de bioética foram introduzidas na grade curricular dos diversos cursos de graduação e pós-graduação em muitas instituições de Ensino Superior do país. Multiplicaram-se programas de capacitação e pós-graduação em bioética e o surgimento de núcleos de pesquisas proporcionaram o aprofundamento das suas bases teóricas e da produção científica nacional $(14,7)$. Dessa forma, nos últimos anos, houve crescimento das atividades relacionadas à bioética e ensino, pesquisa e assistência (7). Entretanto, a inserção da bioética como disciplina nos currículos da área de saúde tem acontecido de forma lenta, fragmentada e assimétrica (8).

No que se refere à fisioterapia, essa dificuldade de inserção parece ainda mais grave. Em 2008, um estudo realizado por Figueiredo (15) contextualizou a situação da bioética nos cursos de pós-graduação stricto sensu em Ciências da Saúde, e demonstrou não haver disciplina de bioética nas áreas de Educação Física, Fisioterapia e Terapia Ocupacional. Na mesma linha, Carneiro (16), em uma análise que delineia o estudo da ética nos cursos de graduação em saúde, constatou que elas ocorriam em apenas quatro profissões - dentre as 14 profissões da área da saúde —, 
Medicina, Enfermagem, Odontologia e Psicologia. Essa talvez seja uma das razões da escassez de publicações que se propõem a fazer uma reflexão bioética sobre as práticas fisioterápicas ou que busquem compreender a visão dos fisioterapeutas sobre os conflitos que emergem dessas práticas.

Em um estudo precursor no Reino Unido, em 1998, Barnitt (17) realizou um questionário para interpretação dos dilemas éticos vivenciados na prática fisioterapêutica e observou que as especialidades de maior conflito profissionais são: a respiratória, a neurológica, a cirúrgica e a ortopédica. Em relação à temática dos dilemas, as categorias encontradas foram: alocação desleal de recursos, eficácia no tratamento, veracidade (dizer ou não a verdade para o paciente), falta de respeito pela opinião do fisioterapeuta e pacientes difíceis.

No Brasil, em 2002, buscando observar essas informações no cenário nacional, Renner e colaboradores (18) entrevistaram 37 fisioterapeutas na cidade de Porto Alegre quanto às situações de dilemas éticos que estão presentes na prática profissional, e os dados encontrados foram: 37,5\% relativos ao limite de atuação profissional, $25 \%$ trataram da falta de recursos, $4,2 \%$ ao ato de não dizer a verdade, $4,2 \%$ sobre a eficiência da terapia. Vale ressaltar que $29,2 \%$, quase um terço dos entrevistados, relatou não ter identificado situações de dilemas éticos em sua prática, o que obviamente pode apontar para uma deficiência de sensibilização e preparação profissional para identificar conflitos éticos e, mais ainda, em agir na direção de sua resolução.

Outros trabalhos no Brasil também têm demonstrado preocupações com situações que implicam na tomada de decisões morais, questões que envolvem a autonomia dos pacientes em fase terminal (19) e o ensino da ética na graduação (20). Entretanto, parece estar sendo mantida uma tendência de fundamentar as discussões, sobretudo no código de ética profissional, limitando-as, portanto, aos seus aspectos deontológicos e legais.

Não obstante, podemos notar que a tomada de decisão em conflitos éticos da prática fisioterapêutica, compreendidos em sua complexidade, implica em uma formação que vai muito além do simples conhecimento dos artigos do código deontológico. 0 Ministério da Educação parece ter compreendido isso também, uma vez que as diretrizes curriculares dos cursos de graduação em Fisioterapia, Fonoaudiologia e Terapia Ocupacional (21) propõem o exercício de competências e habilidades que capacitem o profissional a atuar detendo uma visão ampla e global e respeitando os princípios éticos/bioéticos e culturais do indivíduo e da coletividade. A produção científica nacional na área de fisioterapia tem demonstrado algumas iniciativas acerca do debate sobre a profissão (22), no entanto, ainda é incipiente a produção de trabalhos que abordem o desenvolvimento profissional, na perspectiva das necessidades nas áreas de bioética e saúde coletiva.

Uma bioética para a fisioterapia, nesse sentido, necessita capacitar os profissionais para identificar conflitos éticos em torno de sua prática, inseridos em seus contextos específicos e compreendidos em pelo menos três níveis: o nível sociopolítico-regulatório, referente às condições sociais, quadro epidemiológico e organização da atenção à saúde para a comunidade em que a prática está inserida; o nível institucional, relacionado a decisões administrativas e recursos disponíveis que interferem na produção e resolução desses conflitos; finalmente, o nível interpessoal, que abrange, do lado do paciente, os seus laços culturais e grau de instrução, e, do terapeuta, as competências técnicas e éticas necessárias à sua formação.

Badaró e Guilhem (9) fizeram uma ampla revisão nas pesquisas da área sobre bioética e concluíram que as discussões utilizando teorias e conceitos bioéticos modernos são muito escassos na literatura em fisioterapia. Demonstram, ainda, uma pequena inserção da aplicabilidade desses conceitos na prática clínica. Entretanto, essas autoras fizeram uma busca que incluía também apresentações em congressos, pôsteres e publicações não indexadas. Acreditamos que uma busca específica por artigos publicados em periódicos indexados, realizando um estudo mais aprofundado de seus conteúdos, é de grande importância. Essas publicações, sobretudo com classificação Qualis/ Capes a partir de B2, são submetidas a uma revisão mais rigorosa e têm mais poder de circulação, sendo mais representativas das produções científicas na área e podendo, por conseguinte, representar melhor o pensamento acadêmico na área.

Nesse sentido, um estudo sistematizado do conteúdo dessas publicações - com o intuito de identificar modelos bioéticos utilizados, temáticas privilegiadas, profundidade das análises dos conflitos e proposições de intervenção formuladas pela comunidade científica em fisioterapia preocupada com a questão - poderá ajudar a caracterizar as 
deficiências da área e, consequentemente, contribuir para o planejamento da formação profissional e para uma produção científica mais qualificada na interface entre fisioterapia e bioética.

\section{Materiais e métodos}

Os artigos foram pesquisados nas fontes Biblioteca Regional de Medicina (BIREME) e Scientific Eletronic Library Online (SciELO), com filtros para os anos de 2000 a 2011, utilizando de forma cruzada os descritores: fisioterapia e bioética, e/ou seus derivados: bioético e fisioterápico em ambos os gêneros e no singular e no plural. A escolha das fontes e descritores visava focar os artigos em revistas brasileiras de língua portuguesa com circulação nacional ou latino-americana.

Obteve-se um total de 12 artigos. Desses foram excluídos os artigos que, apesar de conterem os descritores eleitos, tinham ocorrência periférica ao tema central do artigo, e não se pretendia relacionar esses dois campos de saber. Foram excluídos ainda os textos que continham os descritores, mas tratava-se de editoriais e correspondências. 0 corpus de análise ficou reduzido então a um total de cinco artigos, que foram, em seguida, caracterizados quanto ao ano de publicação e Qualis das revistas e submetidos a uma análise de conteúdo pelo método de Bardin (23). Utilizando-se a forma mista de categorização de análise com algumas categorias e subcategorias predefinidas e outras que emergiram das leituras flutuantes, buscou-se examinar a fundamentação teórica dos artigos e suas escolhas temáticas. Os textos foram nomeados de $\mathrm{A} 1$ a $\mathrm{A} 5$.

As categorias e subcategorias ficaram assim constituídas:

1) Conceituação e caracterização da bioética.

2) Identificação de conflitos bioéticos da prática profissional, com três subcategorias: 2.1 Conflitos em relação ao respeito à autonomia do paciente; 2.2 Conflitos em relação à veracidade; 2.3 Conflitos em relação à confidencialidade.

3) Relação interprofissional e intraprofissional.

4) Conflitos em relação à condição clínica do paciente.

5) Necessidades de formação do fisioterapeuta em bioética.

\section{Resultados e discussão}

O Quadro 1 resume a caracterização do corpus de análise, apresentando o ano de publicação, o estado onde estão as instituições às quais os primeiros autores estão vinculados, o tema central dos artigos e o Qualis/Capes das respectivas revistas.

Observa-se que, com exceção do A5, que se trata de um estudo comparado sobre as temáticas das pesquisas em bioética e fisioterapia, os demais artigos que compõem o corpus dirigem-se propriamente a conflitos envolvendo a prática profissional ou sua formação. Vale observar ainda que todos os artigos foram publicados em periódicos classificados em níveis Qualis, considerados pela Capes para quantificar a produção acadêmica. Não houve qualquer regularidade temporal nesta produção, e mesmo que não possa ter significância numérica, chama atenção o fato de que a produção seguiu uma tendência nacional de distribuição regional da produção do conhecimento no país, sendo que quatro dos cinco artigos foram produzidos na região Sul e Sudeste.

\section{Categorias e índices de inferência}

\section{Conceituação e caracterização da bioética}

A bioética teve sua definição conceitual como estudo da conduta humana e como ética aplicada à saúde, às ciências da vida e ao ambiente.

[...] fruto da preocupação ética com questões que dizem respeito à humanidade, surgiu o termo bioética, o qual pode ser conceituado como estudo da conduta humana nas áreas das ciências da vida e dos cuidados da saúde (30).

[...] a bioética, ética aplicada às áreas de saúde e do ambiente (18).

[...] a interdisciplinaridade e a pluralidade são pressupostos fundamentais que permeiam a complexidade da sua construção e discussão, fundamentados na historicidade da Ética (9).

Os conceitos encontrados demonstram algum grau de imprecisão, na medida em que não explicitam as peculiaridades da ética aplicada, nem a distingue do estudo das condutas humanas, conceitualmente mais próximo da filosofia moral e da ética fundamental. Também não foi encontrada nos artigos qualquer 
Quadro 1 - Caracterização do corpus de análise

\begin{tabular}{lllcll}
\hline $\begin{array}{l}\text { Nomeação dos } \\
\text { artigos }\end{array}$ & Tema central & Qualis & Ano de publicação & $\begin{array}{l}\text { Área da } \\
\text { revista }\end{array}$ & $\begin{array}{l}\text { Estado de } \\
\text { origem }\end{array}$ \\
\hline A 1 (19) & $\begin{array}{l}\text { Prática profissional } \\
\text { na UTI }\end{array}$ & B 2 & 2003 & Fisioterapia & Alagoas \\
A 2 (20) & $\begin{array}{l}\text { Bioética e } \\
\text { graduação em } \\
\text { fisioterapia }\end{array}$ & B 2 & 2008 & Fisioterapia & São Paulo \\
A 3 (30) & $\begin{array}{l}\text { A formação ética } \\
\text { do fisioterapeuta }\end{array}$ & B 2 & 2007 & Fisioterapia & Rio de Janeiro \\
A 4 (18) & $\begin{array}{l}\text { Dilemas éticos } \\
\text { da prática } \\
\text { fisioterapêutica }\end{array}$ & B 1 & 2002 & Fisioterapia & Rio Grande do Sul \\
A 5 (9) & $\begin{array}{l}\text { Revisão sobre } \\
\text { pesquisas em } \\
\text { fisioterapia }\end{array}$ & B 2 & 2008 & Fisioterapia & Rio Grande do Sul \\
\hline
\end{tabular}

Fonte: Dados da pesquisa.

preocupação em distinguir deontologia de bioética e, como veremos na apresentação de outras categorias de análise, esses dois campos parecem se interligar de forma um tanto quanto confusa no corpus de textos analisados. Apenas um dos artigos traz elementos de uma fundamentação mais moderna, considerando os aspectos de interdisciplinaridade e complexidade.

Em dois dos cinco artigos analisados não havia qualquer definição conceitual da bioética, e em nenhum dos artigos que constitui o corpus de análise foi possível encontrar referências a tendências teóricas desenvolvidas no Brasil e na América Latina. 0 A5, apesar de ser o único que reconhece o desenvolvimento de modelos com identidade própria no Brasil e na América Latina, não chega a citá-los ou descrevê-los. Assim sendo, os modelos que encontram descrição são os modelos clássicos e hegemônicos, pertencentes à história da bioética.

[...] A importância da proposta inovadora de Potter estava na constituição de uma ética aplicada às situações de vida como caminho para a sobrevivência da espécie humana; esse autor atribuía um sentido marcadamente ecológico ao termo "bioética", que designaria a "ciência da sobrevivência" (19).

A reflexão bioética é baseada nos princípios da bioética que teve origem no relatório Belmont da Comissão Nacional para a proteção dos seres humanos na pesquisa biomédica e comportamental e posteriormente na obra clássica de Beauchamp e Childress (9).
Dois dos três artigos que tentaram conceituar e caracterizar a bioética mostraram-se ainda limitados a aspectos históricos de sua concepção e compreendendo apenas o modelo hegemônico principialista como o fundamento para o raciocínio ético na prática fisioterapêutica. Não foi possível identificar a consideração de uma ética aplicada que, partindo do reconhecimento dos contextos de conflito, levasse em consideração o pluralismo moral e os elos socioculturais e econômicos desses conflitos.

Identificação de conflitos bioéticos da prática profissional

Os conflitos bioéticos da prática profissional são descritos a partir da relação terapeuta-paciente. 0 ambiente de trabalho e a prática profissional dos fisioterapeutas são vistos como situações éticas que implicam em tomada de decisões que necessitam de conhecimento de referenciais da bioética: "[...] os fisioterapeutas, como profissionais pertencentes às ciências da saúde, vivenciam frequentes e diversas situações que implicam a tomada de decisões morais" (19).

0 fato de a prática fisioterapêutica lidar com a possibilidade de trazer benefícios ao paciente, mas ao mesmo tempo ser capaz de provocar danos, é outro elemento que parece justificar a pertinência de desenvolver competências bioéticas nos fisioterapeutas. "[...] o profissional que cuidava do bem-estar das pessoas era extremamente cauteloso em suas ações por 
que, se por um lado poderiam restaura-lhe a saúde, por outro poderiam produzir dano" (30).

A dupla possibilidade "restaurar a saúde e produzir dano" traz à tona dois dos princípios defendidos pela teoria principialista: beneficência e não maleficência. 0 princípio da beneficência destaca a obrigação moral do profissional em sempre "fazer bem" em prol dos seus pacientes, e o da não maleficência se refere à conduta profissional de estar atento aos casos em que, se não for possível fazer o bem, "ao menos, não causar mal". Essa visão traz a questão da necessidade de uma formação técnica adequada e do direito do paciente a um tratamento eficaz, defendido explicitamente por um dos artigos. "[...] 0 paciente tem direito a tratamento eficiente" (18).

Entretanto, não encontramos em nosso corpo de análise nenhuma discussão sobre os limites dos princípios, diferenças de perspectivas sobre estes na visão do terapeuta e do paciente, nem as influências das condições de trabalho nas possibilidades de causar benefício ou dano e na garantia de um tratamento eficiente. Isso demonstra, outra vez, uma tendência ao reconhecimento acrítico do modelo hegemônico principialista como principal instrumento para analisar as relações interpessoais de assistência, sem perceber as influências dos contextos socioeconômico e cultural na geração e potencialização dos conflitos.

Os conflitos mais específicos identificados foram divididos em três subcategorias, tal como apresentado na metodologia: em relação ao respeito à autonomia do paciente; em relação à veracidade das informações fornecidas; em relação à confidencialidade e sigilo.

Conflitos em relação ao respeito à autonomia do paciente

$\mathrm{O}_{\mathrm{s} \text { artigos mostram uma concepçã }}$ do princ $\mathbf{l}_{\text {pio de respeito à }}$ autonomia, tal como definido por $B_{\text {eauchamp e }} C_{\text {hildress }}(4)$, sendo aplicado à prática fisioterap $\hat{e}_{\text {utica traduzida na defesa da liberdade }}$

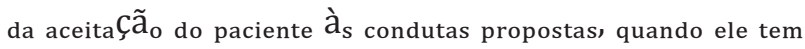

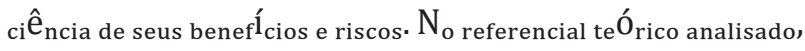

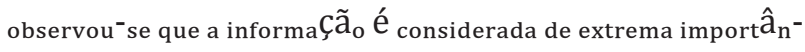
cia para que o princí pio da autonomia seja exercido, estabelecendo

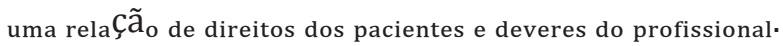
[...] trata-se de uma decisão voluntária, realizada por uma pessoa autônoma e capaz, tomada após processo informativo e deliberativo, visando a aceitação de um tratamento específico, sabendo de sua natureza, de suas consequências e de seus riscos (18).

[...] a informação é a base das decisões autônomas do paciente, necessária para que ele possa consentir ou recusar medidas ou procedimentos de saúde que lhe foram propostos (9).

Pode-se notar claramente a preocupação com os limites físicos e legais da autonomia e com a prevenção de atitudes paternalistas, elementos também muito discutidos na teoria principialista.

[...] quando o paciente está gravemente enfermo, em geral é tratado como alguém sem direito a opinar. [...] embora o paciente tenha se emancipado e é livre para consentir ou não a realização de um tratamento, alguns profissionais ainda tomam por base a conduta paternalista e decidem pelo paciente (9). [...] o fisioterapeuta pode exercer autoridade demasiada com os pacientes, gerando um desequilíbrio que pode impedir um bom relacionamento, devendo pois ser evitado (20).

Observa-se na análise do corpus que a relação paciente-fisioterapeuta, no que diz respeito ao princípio da autonomia, é caracterizada pela busca de equilíbrio entre os direitos dos pacientes em favor das suas escolhas e as obrigações do fisioterapeuta em respeitá-las. No entanto, não encontramos uma análise mais aprofundada sobre a natureza desses conflitos em torno da autonomia, nem a exploração de situações clínicas mais específicas.

Vale ressaltar que não foram encontrados em nosso corpo de análise problemas envolvendo a autonomia do paciente causados por limites da capacidade física ou legal para decidir, mas por influências sobre sua voluntariedade provocadas por situações de vulnerabilidade social, tais como: baixo nível de instrução, dificuldades de acesso a bens e serviços de saúde, condições de submissão social ou diversidade etnocultural. Nesse sentido, também não foi possível notar uma distinção clara entre proteção à vulnerabilidade e paternalismo. Esses temas, comumente examinados pela bioética brasileira e latino-americana, mostram-se ainda distantes dos artigos brasileiros indexados que abordam as relações entre fisioterapia e bioética.

Conflitos em relação à veracidade 
Outros conflitos encontrados no corpus de análise foram aqueles relacionados ao ato de revelar a verdade sobre o prognóstico da doença ao paciente. Nesse caso, a veracidade é apresentada nos artigos como uma obrigação moral. "[...] Não há dilema em dizer ou não dizer a verdade, a verdade é um dever de todo o profissional para com seu paciente" (18).

0 problema parece surgir, então, mais em relação à forma de conduzir essa obrigação moral que propriamente como questionamento sobre o conteúdo de sua justificação, e direciona-se, sobretudo, àquelas circunstâncias em que a informação pode ter impacto negativo sobre a condição do paciente.

[...] O dilema ético presente é de como revelar a má-notícia, que acarreta alteração no futuro do paciente (18).

[...] A complexidade da decisão ética apresenta-se quando há dois pontos relevantes e ações opostas: a veracidade e a compaixão (20).

Dessa forma, esse tipo de discussão surge nos artigos indexados nacionais em uma perspectiva antes deontológica que bioética, pois o próprio Código Deontológico do Fisioterapeuta (24), em seu artigo $7^{\circ}$ e inciso VII, declara que é dever do fisioterapeuta informar ao cliente quanto ao diagnóstico e prognóstico fisioterápico e objetivos do tratamento, salvo quando tais informações possam causar-lhe dano. Não se pode, portanto, identificar qualquer distinção prática nos artigos entre um questionamento bioético e aqueles que se referem à norma deontológica.

0 conflito poderia ter sido analisado, por exemplo, mesmo que pelo modelo principialista, pela compreensão de três princípios prima facie em conflito: o do respeito à autonomia do paciente, orientando o profissional a revelar toda a verdade; o de beneficência, que poderia questionar qual o bem existente em certas formas de verdade; e o da não maleficência, que orienta o profissional de saúde para quando não há ações beneficentes a cumprir ser preferível não agir para evitar o mal.

Se considerarmos, então, uma abordagem mais crítica e socialmente mediada, como é próprio à bioética que vem sendo construída no Brasil e na América Latina, se esperaria uma abordagem que investigasse a possibilidade da informação causar dano, não simplesmente devido ao estado clínico do paciente, mas também de forma integrada aos contextos socioculturais e às formas de vida cotidiana dos pacientes. Nessa perspectiva, precisaria ser discutido também como se dão os jogos de poder entre as diversas categorias que integram as equipes de saúde, em especial da categoria médica, diante da exigência ética de partilha da decisão entre os diversos membros da equipe profissional, o paciente e sua família.

\section{Conflitos em relação à confidencialidade}

É praticamente consensual que confidencialidade é muito importante para a relação terapeuta-paciente, uma vez que, se o paciente acredita que as informações compartilhadas serão respeitadas e utilizadas apenas para a finalidade do tratamento, ele adquire uma confiança no terapeuta indispensável ao tratamento (25). Trata-se, portanto, de um tema esperado nas discussões éticas envolvendo as práticas fisioterapêuticas, e esta expectativa se cumpriu à medida que surge em nosso corpus de análise.

Existe, entretanto, uma distinção conceitual entre confidencialidade e sigilo que não foi feita por nenhum dos artigos, e os dois termos foram tratados quase como sinônimos. Enquanto o primeiro é definido como o respeito à privacidade de uma informação revelada diretamente ao profissional, o segundo refere-se a uma informação privada não diretamente revelada pelo paciente, mas à qual ele teve acesso no exercício da profissão (26). Essa distinção é especialmente importante porque o fisioterapeuta faz parte de uma equipe multidisciplinar de saúde e está inserido em clínicas, hospitais, centros de reabilitação e em outros âmbitos que permitem o contato e a acessibilidade a prontuários e, consequentemente, a informações privadas que não lhe foram reveladas em uma relação de confiança no curso de uma prática assistencial, e que o profissional nem sempre sabe se é obrigado a guardar.

O código deontológico do fisioterapeuta estabelece como dever profissional manter segredo sobre fato sigiloso de que tenha conhecimento em razão de sua atividade profissional (24). Mas, ele não esclarece as situações em que o profissional estará seguro eticamente se, por ventura, houver quebra de sigilo, ou em quais situações a quebra de sigilo poderia acontecer.

Merece destaque o fato de que em nosso corpus de análises, ainda que à semelhança do que ocorreu com a questão da veracidade, não surja uma discussão propriamente bioética da questão da confidencialidade e sigilo. Um dos artigos faz um esforço para ocupar 
os espaços vazios deixados pela norma deontológica: "[...] 0 terapeuta pode aceitar a quebra de sigilo quando houver um imperativo categórico de consciência moral para fazê-lo, ou quando as circunstâncias forem inevitáveis" (20).

Outra vez, não chegam a surgir situações práticas ou exemplos claros em que essa exceção se justifique, como seria mais pertinente a um trabalho de bioética. Dessa forma, o conteúdo do artigo é muito limitado em sua possibilidade de contribuir com o processo de tomada de decisão em situação real. Não é apresentado qualquer tipo de imperativo moral ou de circunstâncias inevitáveis que justificariam a quebra da confidencialidade ou do sigilo. Essas situações, entretanto, já foram enumeradas por outros textos ou capítulos de livros que tratam da bioética no contexto das práticas clínicas, como o de Francisconi e Goldim (27), que enumeram situações como: testemunho em corte judicial, comunicação à autoridade competente sobre a ocorrência de doença, procedimento de informação compulsória, maus-tratos em crianças ou adolescentes ou ferimentos por armas.

Não obstante a essa falta de aprofundamento em situações reais, o artigo também ultrapassa os limites deontológicos ao considerar que algumas dificuldades para manter a confidencialidade não se encontram limitadas apenas à natureza clínica ou legal das circunstâncias, mas podem ser determinadas pelas próprias condições de trabalho, chegando mesmo a criticar o vazio normativo do código deontológico da profissão: “[...] Manter a confidencialidade para os fisioterapeutas é um problema complexo, pois o ambiente e o sistema de trabalho, não favorecem o sigilo das informações, tampouco o código oferece este auxílio" (20).

Apesar de não encontrarmos aqui uma abordagem do problema a partir de referenciais explícitos da bioética, a questão da confidencialidade obteve um tratamento mais abrangente que aquela em torno da veracidade de informações, que foi quase inteiramente limitada à perspectiva deontológica.

\section{Relação interprofissional e intraprofissional}

Estamos chamando de relação interprofissional aquelas que envolvem diferentes categorias profissionais dentro da mesma equipe de saúde, e de intraprofissional aquelas estabelecidas entre colegas fisioterapeutas de uma dada equipe ou instituição.
No que tange à relação interprofissional, encontrou-se destaque para a preocupação com a autonomia da profissão no domínio de suas práticas: "[...] o fisioterapeuta é autônomo para avaliar e decidir a prescrição terapêutica, mesmo que o serviço seja feito por outro profissional" (20).

E com as possibilidades de desvalorização profissional em detrimento de outras categorias profissionais: "[...] outro aspecto que deve ser considerado nesta atual concepção de saúde é a desvalorização do profissional, seja mediante condições desfavoráveis à prática de sua atividade e até mesmo pelo desrespeito entre os profissionais" (30).

Essas preocupações se justificam, sobretudo, pela existência de projetos de lei que poderiam cercear a autonomia da profissão como o do Ato Médico, que se encontra em fase avançada de tramitação e reforça uma situação histórica que estabelece uma compreensão do fisioterapeuta e de outros profissionais da saúde como um tipo de auxiliar ou técnico sempre submisso à conduta médica.

Entretanto, não foram encontrados aspectos da discussão que ultrapassassem esses aspectos deontológicos, corporativos e legais do problema, para além do que já prevê o Código de Ética profissional (24) e o Decreto-Lei n. 938 (28), que regulamentou a profissão e define como atividade privativa do fisioterapeuta "métodos e técnicas fisioterápicos com a finalidade de restaurar, desenvolver e conservar a capacidade física do cliente".

0 mesmo aconteceu com os conteúdos encontrados sobre as relações intraprofissionais. Eles se limitam a discutir a orientação da conduta profissional em respeito à autonomia do colega e diante de erros presenciados, como foi feito pelo artigo 2 de nosso corpus de análise.

[...] respeitar a autonomia do colega de trabalho para traçar conduta de tratamento mediante encaminhamento de pacientes é defendido pelo código. [...] orientar e explicar as regras deontológicas que regem a profissão ao colega que errou para que o fato não se repita é uma atitude de compaixão e respeito (20).

Nota-se claramente também, no que diz respeito aos conflitos éticos que envolvem as relações interpessoais entre profissionais, que as abordagens vêm se apoiando em aspectos deontológicos e legais do problema e não conseguem avançar para 
uma discussão mais ampla, própria da abordagem bioética.

\section{Conflitos em relação à condição clínica do paciente}

É amplamente aceito que as condições clínicas de um paciente têm importância fundamental na geração de conflitos éticos nas práticas assistenciais, e que o conhecimento profundo dessas condições é indispensável a uma boa tomada de decisão. Em consonância com essa perspectiva, em nosso corpus de análise a grande diversidade de inserção do fisioterapeuta e sua área específica de atuação foram consideradas como sendo determinantes diretos dos desafios éticos impostos ao profissional.

[...] dependendo da especialidade do fisioterapeuta, sua atuação pode estar intimamente vinculada ao atendimento de pacientes em condições clínicas graves, em estado terminal e mesmo em situações de risco de vida (19).

[...] no campo da fisioterapia, o profissional lida, na maioria das vezes, com as angústias e dissabores impostos por limitações e sequelas físicas (30).

[...] os problemas éticos da reabilitação são difíceis de definir por serem complexos e de difícil compreensão (18).

O ambiente da Unidade de Terapia Intensiva (UTI) destaca-se como lócus privilegiado para o surgimento de conflitos éticos, impondo ao fisioterapeuta mais desafios em suas tomadas de decisão. Evidenciam-se conflitos éticos clássicos da assistência intensivista como obstinação terapêutica, distanásia, ortotanásia e eutanásia. Um dos artigos de nosso corpus foi mais especificamente dedicado a essa questão.

[...] os fisioterapeutas que trabalham em Unidades de Terapia Intensiva enfrentam essas circunstâncias e, entre elas a problemática do paciente terminal que requer um tratamento específico tanto do ponto de vista técnico, quanto ético. [...] cabe a estes profissionais muitas vezes tomar decisões que envolvam o fim da vida (19).

Ainda que seja importante o reconhecimento desse lócus privilegiado de conflitos que é a UTI, é importante lembrar que o paciente terminal não se encontra apenas nas Unidades de Terapia Intensiva, ele pode estar inserido em instituições de longa permanência, unidades de cuidados paliativos ou submetidos a internamentos domiciliares, em que o fisioterapeuta está sempre presente, e todos esses conflitos ganham outras especificidades. Da mesma forma, a partir do exercício de outras especialidades da fisioterapia, o fisioterapeuta vivencia outras situações conflituosas não necessariamente envolvidas com a terminalidade da vida, mas semelhantes em sua complexidade, tais como as incapacidades físicas, o manejo da dor e enfrentamentos entre a vontade dos pacientes e de suas famílias em relação ao tratamento.

Encontraram-se, entretanto, no corpus de análise, referências muito escassas e pouco variadas sobre as condições em que os conflitos éticos podem surgir e nas quais um olhar bioético se faz necessário. Se observarmos apenas as especialidades profissionais reconhecidas pelo Conselho Federal de Fisioterapia e Terapia Ocupacional (COFFITO) teremos ideia da extensão desse déficit nas publicações indexadas e quanto ainda há para ser explorado na interface entre fisioterapia e bioética. São elas: acupuntura, fisioterapia dermatofuncional, fisioterapia esportiva, fisioterapia do trabalho, fisioterapia neurofuncional, fisioterapia respiratória, fisioterapia oncofuncional, fisioterapia traumato-ortopédica, fisioterapia em saúde da mulher, fisioterapia em saúde coletiva, quiropraxia e osteopatia (24).

Necessidade de formação do fisioterapeuta em bioética

A necessidade de formação profissional em bioética foi reconhecida por três dos cinco artigos que compuseram nosso corpus de análise. A incipiente relação entre fisioterapia e bioética foi reconhecida por um dos artigos, mas sem chegar a fazer propostas de como superar esse estágio de desenvolvimento. “[...] No entanto, é recente a inserção da reflexão bioética sobre a práxis da fisioterápica, ou seja, a apropriação da fundamentação bioética pela fisioterapia" (9).

Outro artigo também identifica a ausência de dados sobre a preparação ética do profissional e seus impactos sobre as praticas. "[...] pouco se sabe sobre o nível de desenvolvimento moral e os efeitos da educação na tomada de decisão na fisioterapia" (20). 
E chega a propor como solução a criação de uma disciplina específica de bioética: "[...] sugere-se ministrar uma disciplina que discute os dilemas éticos da profissão, a bioética, pode permitir aos alunos estabelecer melhor a relação entre os problemas enfrentados e o que é estabelecido pelo código" (20).

Entretanto, a proposta apresentada, além de se distanciar do que a literatura moderna tem defendido no plano da educação em bioética - que é a abolição da estrutura disciplinar em favor de conteúdos curriculares que favoreçam de forma transversal discussões sobre as práticas - , une os conteúdos de bioética com aqueles da deontologia sem considerar a distinção entre as duas áreas.

Siqueira, Zoboli e Kipper (14), por exemplo, defendem que as discussões da bioética devem ser realizadas em toda a formação acadêmica dos profissionais da saúde, considerando que raramente essas questões podem ser instituídas em programas disciplinares fixos, já que questões morais são construídas ao longo do tempo. No mesmo sentido, Muñoz (29) defende que a dimensão da formação profissional em ética se concretiza pela aprendizagem e a vivência da ética em bases não deontológicas, oferecendo ao aluno situações em ele possa refletir ou desenvolver a virtude dos valores humanos em sua prática profissional. A própria Diretriz Curricular Nacional para o curso de Fisioterapia (21), instituída em 2002 pelo Conselho Nacional de Educação, propõe que os cursos desenvolvam conteúdos transversais visando dotar o fisioterapeuta de habilidades e competências que respeitem os limites éticos / bioéticos dos indivíduos e da coletividade.

A distância existente entre a tendência da literatura específica sobre educação em bioética e os artigos até então publicados em revistas nacionais indexadas, que se propõem a discutir essa questão no âmbito da fisioterapia, confirmam o estágio incipiente do desenvolvimento da bioética nessa importante atividade de saúde. Um dos artigos, entretanto, parece aproximar-se mais da atual tendência de transversalidade, quando, apesar de não ter fundamentado sua proposta em alguma referência específica da área, propõe a abertura de espaços de discussão sobre os conflitos vividos: "[...] a inclusão de momentos de discussão e reflexão de aspectos éticos nos cursos de graduação e pós-graduação, portanto, faz-se necessária para que a prática profissional se dê de forma responsável, coerente e adequada" (18).

Isso demonstra que, mesmo intuitivamente, os profissionais da área estão percebendo que o preparo profissional para responder aos desafios éticos da prática fisioterápica no contexto brasileiro - impostos, por um lado, pelo uso frequente de tecnologias de ponta cada vez mais sofisticadas e, por outro, por realidades marcadas por condições de trabalho difíceis e em contextos socioeconômicos desfavoráveis à boa prática - vem determinando exigências de desenvolvimento de competências éticas muito mais complexas que o simples conhecimento do código deontológico pode proporcionar.

\section{Considerações finais}

O trabalho realizado demonstrou o já suspeito grau de incipiência de um pensamento bioético dirigido especificamente à fisioterapia. 0 próprio número de cinco artigos em língua portuguesa publicados em revistas nacionais indexadas já seria suficiente para demonstrar esse estágio bastante tímido do encontro entre essas duas áreas do saber. Entretanto, uma abordagem puramente quantitativa não poderia demonstrar alguns aspectos qualitativos relacionados ao conteúdo dessa produção, como foi aqui realizado.

Existe um limite óbvio em nosso trabalho que é o de ser constituído por um universo de apenas cinco artigos. Contudo, se considerarmos tratar-se dos únicos artigos publicados em revistas indexadas e que todas essas revistas tem nível de qualificação Capes entre B2 e B1 e, portanto, pertencem a um dos extratos mais considerados para a pontuação de qualidade da produção científica, veremos que se justificava uma análise em profundidade dos conteúdos desse conjunto.

É importante mencionar que os temas abordados no corpus da análise vão ao encontro dos resultados da pesquisa de Renner et al. (16), citada na sessão inicial do presente trabalho, que mostrou uma preocupação dos fisioterapeutas brasileiros com temas como os limites de atuação profissional, questões em torno da veracidade e problemas com a eficiência da terapia. Apenas as questões em torno da insuficiência de recursos, que naquele trabalho foi uma preocupação de $25 \%$ dos entrevistados, não chegaram a ser discutidas pelos artigos analisados.

A totalidade dos artigos que abordou a questão das tomadas de decisão na prática assistencial considerou apenas a corrente principialista. Praticamente não houve referência aos espaços públicos consultivos em bioética, como comitês institucionais amplamente defendidos pelas tendências mais modernas 
em bioética clínica, demonstrando que o processo de tomada de decisão na prática fisioterápica parece ainda compreendido como circunscrito à relação entre o terapeuta e seu paciente. Não foi possível também perceber claramente uma distinção entre aspectos bioéticos e deontológicos nos artigos estudados.

Modelos teóricos brasileiros e latino-americanos não foram sequer mencionados nos artigos que abordaram as práticas e a formação profissional. Da mesma forma, em nenhum dos três artigos publicados a partir de 2007 foi encontrada qualquer menção às atuais tendências de desenvolvimento da bioética, apoiadas no referencial teórico-normativo dos direitos humanos e fortemente impulsionadas pela publicação da Declaração de Bioética e Direitos Humanos pela Unesco, em 2005.

Os contextos socioculturais, econômicos ou de organização da atenção à saúde não encontraram nenhuma consideração sobre suas respectivas capacidades de influenciar a geração de conflitos nas práticas assistenciais ou pesquisas. Assim sendo, daqueles três níveis de análise dos conflitos que defendemos como necessários a uma bioética dirigida às práticas clínicas, o sociopolítico, o institucional e o interpessoal, apenas o último foi considerado, com uma discreta consideração das condições de trabalho por um dos artigos que significou uma passagem superficial pelo nível institucional.

Todos os artigos aqui analisados carregam o mérito do pioneirismo, por chamar atenção da categoria por meio de publicações em algumas das melhores revistas da área para a necessidade crescente de unir a bioética ao desenvolvimento teórico, à pesquisa e à prática assistencial da fisioterapia, e demonstraram, por conseguinte, que já existe uma sensibilização dos profissionais para essas carências. Não obstante, o nível ainda primário dos conteúdos mais específicos da teoria bioética e a falta de acompanhamento da evolução epistemológica e prática desse novo campo de saber aponta para a necessidade de desenvolver programas para a capacitação de professores e pesquisadores em fisioterapia para que sejam multiplicadores, tanto na graduação como na pós-graduação, e possam lidar com uma bioética teoricamente bem fundamentada e que seja coerente com a realidade dos principais conflitos éticos na realidade de saúde do Brasil.

\section{Referências}

1. Fabre FA. Bioética: orígenes, presente y futuro. Barcelona: Institut Borja de Bioética; 2001.
2. Durand G. Introdução geral à Bioética: história, conceitos e instrumentos. 2. ed. São Paulo: Loyola; 2007.

3. Neves MPC, Osswald W. Bioética simples. Lisboa: Verbo; 2007.

4. Beauchamp TL, Childress JF. Princípios de ética biomédica. 4. ed São Paulo: Edições Loyola; 2002.

5. GarrafaV.Bioética.In: Giovanella L, EscorelS, Lobato LVC, Noronha JC, Carvalho AI, organizadores. Políticas e sistemas de saúde no Brasil. Rio de Janeiro: Fiocruz; 2008. p. 853-68.

6. Garrafa V, Cordón J, organizadores. Pesquisas em Bioética no Brasil de hoje. São Paulo: Editora Global; 2006.

7. Figueiredo, AM. Perfil acadêmico dos professores de bioética nos cursos de pós-graduação no Brasil. Rev Bras de Edu Médica. 2011 [acesso 9 abr 2012];35(2):163-70. Disponível em: http: / /www.scielo.br/scielo.php?pid=S0100 $-55022011000200004 \&$ script=sci_arttext

8. Figueiredo AM. Profissões da saúde: bases éticas e legais. Rio de Janeiro: Revinter; 2006.

9. Badaró A, Guilhem D. Bioética e pesquisa na Fisioterapia: aproximação e vínculos. Fisioter Pesq. 2008 [acesso 07 abr 2011];15(4):402-7. Disponível em: http://www.scielo.br/pdf/fp/v15n4/15.pdf

10. Garrafa V. Radiografía bioética do Brasil. Acta bioeth. 2000 [acesso 7 abr 2011];6(1):165-9. Disponível em: http://www.scielo.cl/scielo.php?script=sci_ arttext\&pid=S1726-569X2000000100013

11. Porto D, Garrafa V. Bioética de intervenção: considerações sobre a economia de mercado. Revista bioét. 2005 [acesso 2 maio 2012];13(1):111-23. Disponível em: http://revistabioetica.cfm.org.br/index.php/ revista_bioetica/article/view/96/91

12. Schramm FR. Bioética da proteção: ferramenta válida para enfrentar problemas morais na era da globalização. Revista bioét. 2008 [acesso 9 maio 2012];16(1):11-23. Disponível em: http://revistabioetica.cfm.org.br/index. php/revista_bioetica/article/view/52/55

13. Organizações das nações unidas para Educação, Ciência e Cultura - Unesco. Declaração Universal sobre Bioética e Direitos Humanos. Trad. Cátedra Unesco de Bioética da Universidade de Brasília. 2005 [acesso 7 nov 2013]. Disponível em: http://bvsms.saude.gov.br/bvs/publicacoes/declaracao_univ_bioetica_dir_hum.pdf 
14. Siqueira JE, Zoboli E, Kipper DJ, organizadores. Bioética clínica. São Paulo: Gaia; 2008.

15. Figueiredo AM. 0 ensino da Bioética na pós-graduação stricto sensu da área de ciências da saúde no Brasil [tese]. Brasília: Universidade de Brasília; 2009.

16. Carneiro L, Porto C, Duarte S, Chaveiro N, Barbosa MA. 0 ensino da Ética nos cursos de graduação da área de saúde. 2010 [acesso 15 abr 2012];34(3):412-421. Disponível em: http://www.scielo.br/pdf/rbem/ v34n3/11.pdf

17. Barnitt R. Ethical dilemmas in occupational therapy and physical therapy: a survey of practitioners in the UK National Health Service. J Med Ethics. 1998 Jun;24(3):193-9.

18. Renner F, Goldim J, Prati F. Dilemas Éticos presentes na prática do fisioterapeuta. Rev bras fisioter. 2006;6(3):135-8.

19. Araújo L, Neves W. A Bioética e a Fisioterapia nas unidades de terapia intensiva. Rev Fisiot USP. 2003;10(2):52-60.

20. Alves FD, Bigongiari A, Mochizuki L; Hossne WS, Almeida M. 0 preparo bioético na graduação de Fisioterapia. Fisioter Pesqui. 2008 abr/jun [acesso 07 abr 2011];15(2):149-56. Disponível em: http://www.scielo.br/scielo.php?pid=S1809$-29502008000200007 \&$ script $=$ sci_arttext

21. Ministério da Educação (Brasil). Conselho Federal de Educação. Parecer CNE/CES n. 1210/2001. Diretrizes Curriculares Nacionais dos Cursos de Graduação em Fisioterapia, Fonoaudiologia e Terapia Ocupacional. Diário Oficial da União. 10 dez. 2001; Seção 1, p. 22.

22. Nascimento MC, Sampaio RF, Salmela JH, Mancini MC, Figueiredo IM. A profissionalização da Fisioterapia em Minas Gerais. Rev bras Fisioter. 2006 [acesso 8 maio 2012]. 10(2):241-7. Disponível em: http://www. scielo.br/pdf/rbfis/v10n2/v10n2a15.pdf

23. Bardin L. Análise de Conteúdo. Lisboa: Edições 70; 2011.

24. Conselho Federal de Fisioterapia e Terapia Ocupacional - Coffito. Resolução n. 10, de 3 de julho de 1978. Aprova o Código de Ética Profissional de Fisioterapia e Terapia Ocupacional. [acesso em 21 nov 2013]. Disponível em: http://www.coffito.org.br/publicacoes/ pub_view.asp?cod=937\&psecao $=9$
25. Sales-Peres SHC, Sales-Peres A, Fantini AM, Freitas FAR, Oliveira MA, Silva OP, et al. Sigilo profissional e valores éticos. RFO. 2008 [acesso 7 abr 2012];13(1):7-13. Disponível em: http://www.upf.br/seer/index.php/ rfo/article/view/583

26. Loch JA, Clotet J, Goldim R. Privacidade e confidencialidade na assistência à saúde do adolescente: percepções e comportamentos de um grupo de 711 universitários. Rev Assoc Med Bras. 2007 [acesso 23 abr 2012];53(3):240-6. Disponível em: http://www. scielo.br/pdf/ramb/v53n3/a22v53n3.pdf

27. Francisconi CF, Goldim JR. Aspectos bioéticos da confidencialidade e privacidade. In: Costa SIF, Oselka G, Garrafa V. Iniciação à Bioética. Brasília: Conselho Federal de Medicina;1998. p 269-84.

28. Rebelatto JR, Batomé SP. Fisioterapia no Brasil. 2. ed. São Paulo: Manole; 2004.

29. Muñoz DR, Fortes PAC. O princípio da autonomia e o consentimento livre e esclarecido. In: Ferreira SI, Oselka G, Garrafa V. Iniciação à Bioética. Brasília: Conselho Federal de Medicina; 1998. 53-70.

30. Machado D, Carvalho M, Machado B, Pacheco F. A formação ética do fisioterapeuta. Fisioter mov. 2007;20(3):101-5.

Recebido: 05/06/2012

Received: 06/05/2012

Aprovado: 19/07/2013

Approved: 07/19/2013 